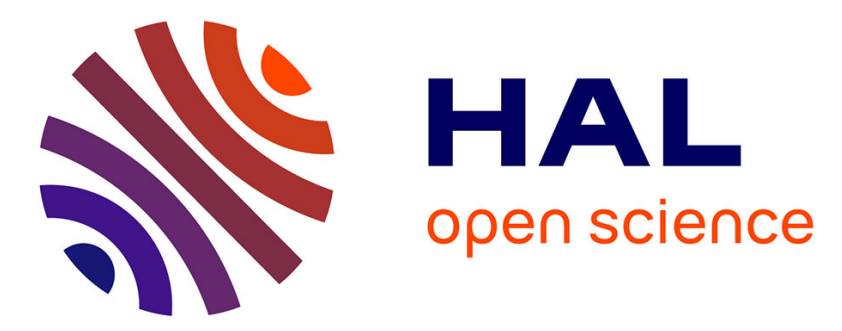

\title{
Local muscular fatigue and attentional processes in a fencing task
}

Marie-Françoise Devienne, Michel Audiffren, Hubert Ripoll, Jean-François

Stein

\section{- To cite this version:}

Marie-Françoise Devienne, Michel Audiffren, Hubert Ripoll, Jean-François Stein. Local muscular fatigue and attentional processes in a fencing task. Perceptual and Motor Skills, 2000, 90 (1), pp.315318. 10.2466/pms.2000.90.1.315 . hal-01757060

\section{HAL Id: hal-01757060 https: / hal-insep.archives-ouvertes.fr/hal-01757060}

Submitted on 3 Apr 2018

HAL is a multi-disciplinary open access archive for the deposit and dissemination of scientific research documents, whether they are published or not. The documents may come from teaching and research institutions in France or abroad, or from public or private research centers.
L'archive ouverte pluridisciplinaire HAL, est destinée au dépôt et à la diffusion de documents scientifiques de niveau recherche, publiés ou non, émanant des établissements d'enseignement et de recherche français ou étrangers, des laboratoires publics ou privés. 


\title{
Local muscular fatigue and attentional processes in a fencing task
}

\author{
Marie-Françoise Devienne ${ }^{1}$, Michel Audiffren ${ }^{2}$, Hubert Ripoll ${ }^{3}$, Jean-François Stein ${ }^{1}$ \\ ${ }^{1}$ Mission Recherche, INSEP Paris, France \\ ${ }^{2}$ Faculté des Sciences du Sport, Université de Poitiers, France \\ ${ }^{3}$ Faculté des Sciences du Sport, Université de la Méditerranée, France
}

\begin{abstract}
Summary
Study of the effects of brief exercise on mental processes by Tomporowski and Ellis (1986) has shown that moderate muscular tension improves cognitive performance while low or high tension does not. Improvements in performance induced by exercise are commonly associated with increase in arousal, while impairments are generally attributed to the effects of muscular or central fatigue. To test two hypotheses, that (1) submaximal muscular exercise would decrease premotor time and increase motor time in a subsequent choice-RT task and (2) that submaximal muscular exercise would increase the attentional and preparatory effects observed in premotor time 9 men, aged 20 to 30 years, performed an isometric test at $50 \%$ of their maximum voluntary contraction between blocks of a 3-choice reaction-time fencing task. Analysis showed (1) physical exercise did not improve postexercise premotor rime, (2) muscular fatigue induced by isometric contractions did not increase motor time, (3) there was no effect of exercise on attentional and preparatory processes involved in the postexercise choice-RT task. The invalidation of hypotheses was mainly explained by disparity in directional effects across subjects and by use of an exercise that was not really fatiguing.
\end{abstract}

Study of the effects of brief exercise on mental processes have shown that moderate muscular exercise improves cognitive performance while low or high muscular exercise neither improves nor impairs it (for a review, see Tomporowski \& Ellis, 1986; Brisswalter \& Legros, 1996). Improvement is commonly associated with increased arousal and activation, while impairment is generally attributed to the effects of muscular or central fatigue.

The present aim was to study the influence of repeated isometric contractions on cognitive performance. To study the differentiated effects of local muscular fatigue and of increasing arousal and activation, we used the fractionated reaction-time technique (Botwinick \& Thompson, 1966). According to the discrete stage model of Sternberg (1969), we hypothesized that a factor which selectively influences the central stages of information processing would affect premotor time but not motor time. Thus, increased arousal, induced by a physical exercise, would decrease premotor time without affecting motor time. In other respects, Stull and Kearney (1978) showed motor time increased with fatigue. Thus, muscular fatigue should negatively influence motor time without affecting premotor time.

In addition, we hypothesize that an increase in arousal and activation induced by exercise enhances the orienting of visual attention and of motor preparation involved in a priming procedure (Posner, 1980; Rosenbaum \& Kornblum, 1982). In this procedure, information (prime), related to the forthcoming location of a response signal and to the forthcoming movement, is presented to the subject before the response signal. This information can allow the subject to set, during the preparatory period, visual attention and motor preparation processes with the aim of reducing the reaction time. The preliminary information can be valid or invalid, that is to say, it can bring exact or erroneous information on location of the response signal and parameter values of the forthcoming movement. The difference between invalid and valid primes has been described in terms of the mental operations involving engagement, disengagement, switching, and reengagement of attention (Posner, 1980) or the programming, deprogramming, and reprogramming of movement (Rosenbaum \& Kornblum, 1982). We expected that an increase in arousal and activation would increase availability of attentional and preparatory resources, and of differences between performances recorded for valid and invalid priming. 


\section{Method}

Nine male volunteers $(M$ age $=25$ yr., $\mathrm{SD}=3.8)$ participated. Subjects confronted a 3-choice reaction time task which consisted of reaching a target with a sword when a light-emitting diode was illuminated. The task was executed using ARVIMEX (Nougier, Azemar, \& Stein, 1990) which analyzes visuomotor reactions in fencing. The fatigue of the triceps brachii was measured by the median frequency obtained from electromyography (De Luca, 1984). The experiment was composed of a baseline and an exercise session. The baseline session was composed of five blocks of 90 trials with a rest period between blocks. The exercise session was composed of five blocks of 90 trials with an isometric contraction between blocks performed at $50 \%$ of the maximal voluntary contraction. The order of the two sessions was randomized. To obtain attentional effects, each block of 90 trials included 24 trials with a valid prime and six trials with an invalid prime for each of the three targets.

\section{Results and discussion}

We predicted that physical exercise would induce two different effects on the choice-reaction time task. On the one hand, the muscular fatigue should impair motor time without affecting premotor time. On the other hand, an increase in arousal and activation induced by physical exercise should decrease premotor time without affecting motor time. These two effects might decrease premotor time and increase motor time.

The shift of the median frequency to a low frequency was not significant, although the exhaustion times in executing a 50\% isometric contraction with the triceps brachii decreased significantly between the pre- $(\mathrm{M}=86 \mathrm{sec} ., S D=26)$ and posttest conditions $(\mathrm{M}=61 \mathrm{sec} ., S D=14)$. Contrary to our expectations and to the results of a previous study (Stull \& Kearney, 1978), no deterioration in motor time was observed in the last block of trials after the isometric contraction. As the sample of subjects was composed of well conditioned athletes, the $50 \%$ isometric fatigue task was probably not severe enough relative to fatigue.

Studies of the effect of brief exercise on mental processes have shown that moderate muscular tension improves cognitive performance whereas high or low tension has no effect (Tomporowski \& Ellis, 1986). It is important to emphasize that in all these studies mental tasks were carried out simultaneously with muscular contractions. The only study of postexercise effects showed an increase in visual threshold after an isometric contraction (Krus, Wapner, \& Werner, 1958).

Despite the choice of moderate physical exercise, we have observed no variation in performance on the reaction-time task. This lack of positive effect on premotor time could reflect greater variability in the directional effect across subjects or lack of effect for all subjects. An analysis of individual records showed that during the first trial block, premotor time increased for six subjects whereas the premotor time decreased for three subjects. Such an analysis clearly shows that the lack of a significant effect of exercise reflected between-subjects variability. Perhaps initially, arousal varied with their different personality traits, motivation, or time of day in which they participated. In accordance with Posner (1980) and Rosenbaum and Kornblum (1982), voluntary orienting of attention and preparation induced by a valid prime before the signal response facilitated subjects' reaction time, premotor time, and movement time ( $\mathrm{F}_{1,8}=83.2,12.5$, and 55.6, respectively). This result could be interpreted in two ways. From Posner's perspective (1980), the engagement of attention during stimulus onset asynchrony, given a valid prime, involves decreased reaction time. Given an invalid prime, disengagement, switching, and reengagement of attention increases reaction time. In contrast, Rosenbaum and Kornblum (1982) would argue that the programming of movement during the foreperiod, given a valid prime, facilitates reaction time. Deprogramming and reprogramming of movement that takes place, given an invalid prime, impairs reaction time.

The priming effect did not interact with block or session. Consequently, our second hypothesis that a submaximal muscular exercise would increase attentional and preparatory effects observed in premotor time was not validated. As we expected, motor time which reflects the muscular electromechanical transduction time was not affected by the nature of the prime. 


\section{References}

BOTWINICK, J. \& THOMPSON L., (1966) Premotor and motor components of reaction time. Journal of Experimental Psychology, 7 1, 9- 15.

BRISSWALTER, J., \& LEGROS, P., (1966) Interactions entre les processus physiologiques et cognitifs: problèmes théoriques et méthodologiques. Science et Sports, 11, 71-80.

DE LUCA, C. J. (1984) Myoelectrical manifestations of localized muscular fatigue in humans. CRC Biomedical Engineering, 11, 251-279.

HEBB, D. O. (1955) Drives and the CNS (Conceptual Nervous System). Psychological Review, 62, 243-254.

KRUS.D . M., WAPNER, S. \& WERNER H,. (1958) Studies in vicariousness: the effect of muscular involvement on visual threshold. American Journal of Psychology, 71, 395-398.

NOUGIER, V., AZEMAR, G. \& STEIN, J.-F. (1990) Covert orienting of attention and motor preparation processes as a factor of success in fencing. Journal of Human Movement studies; 19, 251272.

POSNER, M. I. (1980) Orienting of attention. Quarterly Journal of Experimental Psychology, 32, 325 .

ROSENBAUM. D.A. \& KORNBLUM, S. ( 1982) A priming method for investigating the selection of motor responses. Acta Psychologica, 50, 223-224.

STERNBERG, S. ,( 1969) The discover of processing stages: extensions of Donders' method. In W. Koster (Ed.), Attention and performance II Amsterdam: North-Holland. pp. 276-315.

STULL, G. \& KEARNEY, J.. (1978) Effects of variable fatigue levels on reaction-time components. Journal of Motor Behavior, 10, 223-231.

TOMPOROWSKI, P.D. \& ELLIS, N. R. (1986) Effects of exercise on cognitive processes: a review. Psychological Bulletin, 99, 338-346. 